\title{
Prevalence of Post Traumatic Amnesia after Mild Closed Traumatic Brain Injury by Galveston Orientation and Amnesia Test
}

\author{
SYED SHAHZAD HUSSAIN, ${ }^{1}$ USMAN AHMAD KAMBOH, ${ }^{1}$ MUHAMMAD ASIF RAZA, ${ }^{1}$ \\ MUHAMMAD SHAHZAD, ${ }^{1}$ SAMAN SHAHID, ${ }^{2}$ NAVEED ASHRAF ${ }^{1}$ \\ ${ }^{1}$ Department of Neurosurgery, Jinnah Hospital, ${ }^{2}$ National University of Computer \& Emerging Sciences \\ (NUCES), Lahore, Pakistan
}

DOI: https://doi.org/10.36552/pjns.v23i3.354

\begin{abstract}
Objective: We evaluated the frequency of post traumatic amnesia (PTA) in close mild traumatic brain injury (TBI) via. Galveston Orientation and Amnesia Test (GOAT).

Materials \& Methods: A total of 115 patients with mild TBI, both male and female, aged between 14 to 60 years and presenting within the first 6 hours were included. Assessment with the GOAT was performed within 6 hours of admission. Post traumatic amnesia was recorded.
\end{abstract}

Results: Patients' mean age was 39.21 years. Majority of the patients (64.34\%) were between 36- 60 years of age. Prevalence of post traumatic amnesia (PTA) in closed mild TBI was found in $27.83 \%$ patients, whereas, there was no post traumatic amnesia in $72.17 \%$ patients. Mean admission GCS was 14.54 and the mean GOAT score was 83.89 in all patients GCS 14/15. There was more prevalence of PTA in age 36-60 years, in male patients and "time since injury" in $>3$ hours. Mean GOAT was 68.3 in patients (30.19\%) with PTA with GCS 14, whereas, mean GOAT was 74.8 in patients (25.80\%) with PTA with GCS 15.

Conclusion: $30.19 \%$ patients with GCS 14, were positive for PTA (GOAT: 68.3). Overall, 28\% patients were positive for PTA. This study concluded that prevalence of post traumatic amnesia in mild TBI is relatively high in our study as compared to other recent reports.

Abbreviations: TBI: Traumatic Brain Injury. PTA: Post Traumatic Amnesia. GOAT: Galveston Orientation and Amnesia Test. GCS: Glaucoma Outcome Scale. LOC: Loss of Consciousness. CT: Computed Tomography.

Keywords: Traumatic brain injury (TBI), Post traumatic amnesia (PTA), Galveston Orientation and Amnesia Test (GOAT).

\section{INTRODUCTION}

We evaluated the frequency of post traumatic amnesia (PTA) in mild closed traumatic brain injury (TBI) along with the assessment of any significant co factor. Traumatic brain injury is a leading cause of presentation to emergency departments with an estimated incidence of 54-60 million people/year worldwide. ${ }^{1}$ It is a major chronic disability in adults and children. By 2020, it would become a third common burden of disease worldwide. ${ }^{2}$ The overall impact of traumatic brain injury is grave in developing countries, where poverty, illiteracy, lack of access to proper health care and negligence engender significantly worse outcomes. The annual incidence of head injury in Pakistan is around 50/100,000 population. ${ }^{3}$ Bhatti et al. (2015) reported in Pakistan, that every TBI patient spent about on average $8.4 \$$ in the emergency management in Pakistan. ${ }^{4}$

Traditionally traumatic brain injury is classified as mild, moderate or severe, based on the consciousness level, duration of loss of consciousness (LOC) and PTA. Eighty to ninety percent of the patients present 
with the GCS of $14-15$ and are considered as mild traumatic brain injuries. ${ }^{6}$ Mild traumatic brain injury occurs in LOC $<30$ minutes and post traumatic amnesia (PTA) of $<24$ hour. Majority patients usually recover from mild TBI within days or months, but $15 \%$ patients may still develop persistent disabilities such as, decreased functional capacity, emotional distress and delayed return to work. ${ }^{7}$ This results in impairment of acts of daily living and professional, personal and social responsibilities. Post traumatic amnesia (PTA) is an appropriate tool to evaluate head trauma severity, as the majority of the patients with concussion quickly regain a GCS score of 15 after concussion. ${ }^{8}$ There are several tools which can evaluate head trauma patients for post traumatic amnesia. ${ }^{9}$ Relying solely on the GCS score would mean that the incidence of mild traumatic injury would be underestimated. In Pakistan, most of the tools for trauma identification are not yet properly standardized and hence an improper management can under evaluate the effects of mild TBI which could lead to an increased morbidities. A proper assessment tool for post traumatic amnesia in the emergency department can present the proper outcomes in patients. The significant features of post traumatic amnesia are disorientation and anterograde amnesia along with the presentation of behavioral disturbance, confusion, delirium, abnormality in attention, retrograde amnesia. ${ }^{8}$

The GOAT test was designed by Levin et al. in 1979.It is used to evaluate the recovery phase of the patients ${ }^{9}$. It is beneficial in the clinical findings to evaluate the span of post-traumatic amnesia. The findings from GOAT evaluation can strongly predict functional outcome as measured by the GCS, return to productivity and functionality. ${ }^{9}$ We employed Galveston Orientation and Amnesia Test (GOAT), as relying solely on the GCS score means that the incidence of mild traumatic injury would be underestimated. The GOAT is widely used standard measure to assess of PTA. ${ }^{10,14}$ GOAT assessment is a good measure to anticipate functional outcome and psychosocial variations. ${ }^{11,14}$ There is a paucity of clinical data regarding the prevalence of the PTA after mild TBI in Pakistan. This translates into lack of identification of a large majority of patients who will have persistent disabilities. The aim of the study was to establish the prevalence of PTA in closed mild TBI and provide a positive impact on the outcome of these patients.

\section{MATERIALS \& METHODS}

\section{Study Design and Sampling}

A cross sectional study was conducted at the Neurosurgery Department, Jinnah Hospital Lahore from January 2017 to December 2017, to evaluate the frequency of post traumatic amnesia (PTA) in closed mild traumatic brain injury (TBI).A sample size of $n=$ 115 was evaluated with $95 \%$ confidence interval and $6 \%$ of margin of error. ${ }^{2}$

\section{Inclusion Criteria}

Age 14 - 60 years of either gender. Included cases of closed mild traumatic brain injury (GCS 14 or above) presenting within first 6 hours.

\section{Exclusion Criteria}

Subjects with poly trauma, co morbidities, and penetrating injury brain were excluded. Intoxicated subjects, subjects with mental retardation, developmental delay, attention deficit, hyperactivity disorder or learning disability on clinical examination were also excluded.

\section{Data Collection GCS \& GOAT}

The GOAT test includes sixteen questions. With a score of $\geq 75$ for two consecutive days, the patient is no longer in the post-traumatic amnesia phase. If the score is between $66-75$, the patient then has a borderline status, and if the score is $<66$, the patient can be still evaluated in the post-traumatic amnesia phase. ${ }^{9}$

In this study, a total115 subjects fulfilling the inclusion and exclusion criteria were recruited for the study after taking informed consent from patient or relatives. Assessments with the Galveston orientation and Amnesia test (GOAT) were performed within 6 hours of admission. The total GOAT score was obtained Total Score $=100-$ Total Error Points. ${ }^{9,14}$ With the score $<75$, the patient is not with a PTA stage. With the score < 75, a patient considers a positive forPTA. ${ }^{9}$ Glasgow Coma Score (GCS) and the time since injury at the time of GOAT assessment were recorded. All the data was entered on predesigned Proforma and post traumatic amnesia was recorded. 


\section{Data Analysis Procedure}

The data was entered and analyzed in SPSS 23. Means and standard deviations were calculated for quantitative variables like age, time since injury, GOAT score and GCS. Frequencies and percentages were calculated for qualitative variable gender. Data was stratified for age, gender, time since injury $(<3$ or $>3$ hours) to address effect modifiers. Chi square test was applied to find out any statistically significant co factors of PTA with respect to different groups. A pvalue of 0.05 was considered as significant.

\section{RESULTS}

Age range was from 14 to 60 years with a mean of $39.21 \pm 9.28$ years. Majority of the patients 74 $(64.34 \%)$ were between 36 to 60 years (Table 1). Out of the 115 patients, $68(59.13 \%)$ were male and 47 $(40.87 \%)$ were females. Mean time since injury was $3.69 \pm 1.22$ hours (Table 2). Mean admission GCS

Table 1: Age distribution of patients $(n=115)$.

\begin{tabular}{|c|c|c|c|}
$\begin{array}{c}\text { Age (in } \\
\text { Years) }\end{array}$ & $\begin{array}{c}\text { No. of } \\
\text { Patients }\end{array}$ & \%age & Mean \pm SD \\
$14-35$ & 41 & 35.65 & $39.21 \pm$ \\
\cline { 1 - 3 } $36-60$ & 74 & 64.34 & 9.28 years \\
\hline
\end{tabular}

Table 2: Distribution of Patients According to Time since Injury $(n=115)$.

\begin{tabular}{|c|c|c|c|}
\hline $\begin{array}{c}\text { Time Since } \\
\text { Injury (Hours) }\end{array}$ & $\begin{array}{c}\text { No. of } \\
\text { Patients }\end{array}$ & \%age & Mean \pm SD \\
\hline$\leq 3$ hours & 68 & 59.13 & $3.69 \pm 1.22$ \\
hours \\
\hline
\end{tabular}

was $14.54 \pm 0.50$ (Table 3). Prevalence of post traumatic amnesia (PTA) in mild traumatic brain injury (TBI) was found in $32(27.83 \%)$ patients. Whereas, there was no post traumatic amnesia in 83 $(72.17 \%)$ (Table 4).

Table 3: Distribution of patients According to GCS $(n=115)$.

\begin{tabular}{|c|c|c|c|}
\hline GCS & No. of Patients & \%age & Mean \pm SD \\
14 & 53 & 46.08 & $14.54 \pm$ \\
\cline { 1 - 3 } 15 & 62 & 53.91 & 0.50 \\
\hline
\end{tabular}

Table 4: Prevalence of Post Traumatic Amnesia in Mild Traumatic Brain Injury (TBI) $(n=$ 115).

\begin{tabular}{|l|c|c|}
\hline Prevalence PTA & No. of Patients & \%age \\
\hline Yes & 32 & 27.83 \\
No & 83 & 72.17 \\
\hline
\end{tabular}

No significant difference was found in stratification in following all groups: age, gender, admission GCS $14 / 15$, time since injury ( $\leq 3$ hours $/>3$ hours) at $\mathrm{p}$ values: $0.270,0.189,0.300,0.696$ respectively (Tables 5-8).Overall, mean GOAT score was $83.89 \pm 9.42$ in both GCS 14 and 15 in all patients (Table 7). Mean GOAT was 68.3 in patients (30.19\%) with PTA with GCS 14, whereas, mean GOAT was 74.8 in patients $(25.80 \%)$ with PTA with GCS 15 (Table 7). With GOAT value: 68.3 (i.e., < 75), $30.19 \%$ patients $(\mathrm{n}=53)$ who were having GCS 14 , were positive for PTA. Overall, $28 \%$ patients $(n=32)$ were positive for PTA.
Table 5: Stratification of Post Traumatic Amnesia (PTA) With Respect to Age Groups.

\begin{tabular}{|l|l|l|l|}
\multirow{2}{*}{ Age (Years) } & \multicolumn{2}{|l|}{ Post Traumatic Amnesia (PTA) } & \multirow{2}{*}{ p-value } \\
\cline { 2 - 3 } & Yes & No & \\
\hline $14-35(\mathrm{n}=41)$ & $10(24.39 \%)$ & $31(75.61 \%)$ & \multirow{0}{*}{$\mathbf{0 . 2 7 0}$} \\
\hline $36-60(\mathrm{n}=74)$ & $22(29.73 \%)$ & $52(70.27 \%)$ & \\
\hline
\end{tabular}

There was more prevalence $(29.73 \%)$ of PTA in age 36-60 years as compared to age group 14-35 years. There was more $(30.88 \%)$ prevalence of PTA in male patients as compared to female patients. There were more patients $(30.19 \%)$ with admission GCS 14 in PTA as compared to GCS 15. There was more prevalence $(29.79 \%)$ of PTA in "time since injury" in $>3$ hours. 


\section{GOAT in Relation with CT Scan Findings}

$25.2 \%(\mathrm{n}=29)$ of the total sample did not undergo computed tomography because they did not fulfill the indications for CT scan. Of the remaining sample $(n=86), 18$ patients (20.9\%) had abnormality on CT Scan and this group had a mean GOAT score of 83.5. 68 patients $(79.1 \%)$ had a normal CT Scan and this group had a mean GOAT score of 88.3.
Table 6: Stratification of post traumatic amnesia (PTA) With Respect to Gender.

\begin{tabular}{|l|c|c|c|}
\multirow{2}{*}{ Gender } & \multicolumn{2}{|c|}{ Post Traumatic Amnesia (PTA) } & \multirow{2}{*}{ p-value } \\
\cline { 2 - 3 } Male $(\mathrm{n}=68)$ & Yes & No & \\
\cline { 2 - 3 } & $21(30.88 \%)$ & $47(69.12 \%)$ & \multirow{2}{*}{0.189} \\
\hline
\end{tabular}

Table 7: Stratification of Post traumatic amnesia (PTA) with Respect to Admission GCS.

\begin{tabular}{|l|c|c|c|c|c|}
\hline \multirow{2}{*}{ Admission GCS } & \multicolumn{4}{|c|}{ Post Traumatic Amnesia (PTA) } & \multirow{2}{*}{ p-value } \\
\cline { 2 - 5 } & Yes & Mean GOAT & No & Mean GOAT & \\
\hline $14(\mathrm{n}=53)$ & $16(30.19 \%)$ & 68.3 & $37(69.81 \%)$ & 94.4 & \multirow{2}{*}{0.300} \\
\hline $15(\mathrm{n}=62)$ & $16(25.80 \%)$ & 74.8 & $46(74.20 \%)$ & 98.1 & \\
\hline
\end{tabular}

\section{DISCUSSION}

The aim of the study was to evaluate the prevalence of post traumatic amnesia (PTA) in closed mild TBI with the assessment of any significant co factor. A post traumatic amnesia (PTA) is considered as a state of disorientation, confusion and memory loss progress from a head injury. Its pathophysiological and clinical means are not clearly understood. Alterations in hippocampus \& temporal lobes, ischemia, edema and perfusion abnormalities are major parameters in posttraumatic amnesia ${ }^{8}$. We have conducted this study to evaluate the prevalence of post traumatic amnesia in mild traumatic brain injury. Mean admission GCS was 14.54 and the mean GOAT score was 83.89. Most of the patients with GCS score 14 (30\%) were positive for PTA as compared to GCS 15 . However, overall, the prevalence of PTA in our study was $28 \%$. There was more prevalence of PTA in age 36-60 years, in male patients and "time since injury" in $>3$ hours. The result is comparable with study of Stead et al. (2013) ${ }^{2}$ according to which the prevalence of PTA after TBI is $25.6 \%{ }^{2}$ Our study showed that the prevalence of PTA after mild TBI is relatively high as compared to other recent studies, for example, Foks et al. (2019) ${ }^{12}$ reported that PTA was absent in $72 \%$, not documented in $7 \%$ and therefore, it was confirmed to be present in $21 \%$. We could not establish any significant relation with co-factors (age, gender, GCS or time since injury). A valid tool for the assessment of PTA is required in patients with head injuries presenting to emergency departments. These mild TBI would have been incorrectly classified, if only a GCS tool would have been used and hence, these patients would be at higher risk of disabilities like post-concussive syndrome etc. The outcome is usually poor in mild TBI patients with post traumatic injury. ${ }^{13}$

There is great paucity of data on the epidemiology of TBI in our country. The epidemiological data is an essential tool for identifying the target populations at risk. As such, in the absence of usage of proper tools for identifying PTA in patients with HI, many patients can end up not being identified correctly as having mild TBI. Up to $85 \%$ cases of mild traumatic brain injury account for all types of other traumatic brain injuries. Many disabilities are related to mild traumatic brain injuries with a poor outcome. Disturbed 
pathologies are reported from mild TBI patients. Stead et al. (2013) reported $21 \%$ cases of bleed, $13 \%$ cases of fractures on $\mathrm{CT}$, around $4 \%$ rates of neurosurgical intervention and around $1 \%$ death rate. ${ }^{2}$ This study highlights the need for the use of a validated tool for the assessment of PTA in patients with head injury in the emergency department of hospitals in order to identify a large majority of patients who will have persistent disabilities.

\section{RECOMMENDATION}

We also recommend that there should be an early recognition of patients with post traumatic amnesia in mild traumatic brain injury to ensure proper management of these particular patients in order to improve the outcome. Moreover, further studies should be done to assess the percentage of patients with post traumatic amnesia who later develop the post concussive syndrome.

\section{CONCLUSION}

The $30.19 \%$ patients (GCS 14), were positive for PTA (GOAT: 68.3). Overall, 28\% patients were positive for PTA. This study concluded that prevalence of post traumatic amnesia in mild TBI is relatively high in our study as compared to other recent reports. We recommend that a validated tool based assessment of post traumatic amnesia (PTA) should be done in all patients with head injury.

\section{Additional Information}

Disclosures: Authors report no conflict of interest.

Human Subjects: Consent was obtained by all patients/ participants in this study.

\section{Conflicts of Interest:}

In compliance with the ICMJE uniform disclosure form, all authors declare the following:

Financial Relationships: All authors have declared that they have no financial relationships at present or within the previous three years with any organizations that might have an interest in the submitted work.

Other Relationships: All authors have declared that there are no other relationships or activities that could appear to have influenced the submitted work.

Address for Correspondence: Dr. Syed Shahzad Hussain, Department of Neurosurgery, Jinnah Hospital, Lahore, Pakistan Email:drshahzadns@yahoo.com

\section{REFERENCES}

1. Feigin V, Theadom A, Barker-Collo S, Starkey N, McPherson K, Kahan M et al. Incidence of traumatic brain injury in New Zealand: a population-based study. The Lancet Neurology, 2013; 12 (1): 53-64.

2. Stead L, Bodhit A, Patel P, Daneshvar Y, Peters K, Mazzuoccolo A et al. TBI surveillance using the common data elements for traumatic brain injury: a population study. International Journal of Emergency Medicine, 2013; 6 (1): 5.

3. Umerani MS, Abbas A, Sharif S.Traumatic brain injuries: experience from a tertiary care centre in Pakistan.Turk Neurosurg. 2014; 24 (1): 19-24.

4. Bhatti J, Stevens K, Mir M, Hyder A, Razzak J. Emergency care of traumatic brain injuries in Pakistan: a multicenter study. BMC Emergency Medicine, 2015; 15 (Suppl. 2): S12.

5. Barman A, Chatterjee A, Bhide R. Cognitive impairment and rehabilitation strategies after traumatic brain injury. Indian J Psychol Med. 2016; 38 (3): 172.

6. Bosch M, McKenzie J, Mortimer D, Tavender E, Francis J, Brennan $\mathrm{S}$ et al. Implementing evidencebased recommended practices for the management of patients with mild traumatic brain injuries in Australian emergency care departments: study protocol for a cluster randomised controlled trial. Trials, 2014; 15 (1): 281.

7. Ponsford J, Cameron $\mathrm{P}$, Fitzgerald $\mathrm{M}$, Grant $\mathrm{M}$, Mikocka-Walus A. Long-Term Outcomes after Uncomplicated Mild Traumatic Brain Injury: A Comparison with Trauma Controls. Journal of Neurotrauma, 2011; 28 (6): 937-946.

8. Nakase-Richardson R, Sherer M, Seel R, Hart T, Hanks $\mathrm{R}$, Arango-Lasprilla $\mathrm{J}$ et al. Utility of post-traumatic amnesia in predicting 1-year productivity following traumatic brain injury: comparison of the Russell and Mississippi PTA classification intervals. Journal of Neurology, Neurosurgery \& Psychiatry, 2011; 82 (5): 494-499.

9. Moin P, Khalighinejad N, Yusefi A, Farajzadegan Z, Barekatain M. Converting three general-cognitive function scales into persian and assessment of their validity and reliability. Int J Prev Med. 2011; 2: 82-7.

10. Frasnelli J, Laguë-Beauvais M, LeBlanc J, Alturki A, Champoux M, Couturier $\mathrm{C}$ et al. Olfactory function in acute traumatic brain injury. Clinical Neurology and Neurosurgery, 2016; 140:68-72.

11. Thomas D, Collins M, Saladino R, Frank V, Raab J, Zuckerbraun N. Identifying Neurocognitive Deficits in Adolescents Following Concussion. Academic Emergency Medicine, 2011; 18 (3): 246-254.

12. Foks KA, Dijkland SA, Steyerberg EW. Response to Walker et al. (Doi: 10.1089/neu. 2017.5359): Predicting long-term global outcome after traumatic brain injury. Journal of neurotrauma, 2019; 36 (8): 1382-3. 
13. Ponsford JL, Spitz G, McKenzie D. Using posttraumatic amnesia to predict outcome after traumatic brain injury. Journal of neurotrauma, 2016; 33 (11): 997-1004.
14. Silva SCF, Sousa RMCd. Galveston orientation and amnesia test: applicability and relation with the Glasgow Coma Scale. Revista latino-americana de enfermagem. 2007; 15 (4): 651-7.

\begin{tabular}{|c|c|c|c|}
\hline \multicolumn{4}{|c|}{ AUTHORSHIP AND CONTRIBUTION DECLARATION } \\
\hline Sr.\# & Author's Full Name & Intellectual/Contribution to Paper in Terms of: & \multirow{4}{*}{$\begin{array}{l}\text { Signature by the } \\
\text { author(s) }\end{array}$} \\
\hline 1. & $\begin{array}{l}\text { Syed Shahzad Hussain } \\
\text { (Main/Principal Author). }\end{array}$ & $\begin{array}{l}\text { 1. Proposed topics and Basic Study Design, } \\
\text { methodology. }\end{array}$ & \\
\hline 2. & $\begin{array}{l}\text { Usman Ahmad Kamboh } \\
\text { (2nd Author) }\end{array}$ & \multirow{2}{*}{$\begin{array}{l}\text { 2. Data collection and calculations } \\
\text { 3. Analysis of data and interpretation of results etc. }\end{array}$} & \\
\hline 3. & $\begin{array}{l}\text { Muhammad Asif Raza } \\
\text { (3rd Author) }\end{array}$ & & \\
\hline 4. & $\begin{array}{l}\text { Muhammad Shahzad } \\
\text { (4th Author) }\end{array}$ & \multirow{3}{*}{$\begin{array}{l}\text { 4. Literature review and manuscript writing } \\
\text { 5. Paper writing, referencing, Data Calculations and } \\
\text { quality insurer }\end{array}$} & \\
\hline 5. & $\begin{array}{l}\text { Saman Shahid } \\
\text { (5th Author) }\end{array}$ & & \\
\hline 6. & $\begin{array}{l}\text { Naveed Ashraf } \\
\text { (6th Author) }\end{array}$ & & \\
\hline
\end{tabular}

Date of Submission: 06-07-2019

Date of Revision: 30-07-2019

Date of Online Publishing: 25-09-2019

Date of Print: 30-09-2019 